\title{
Acute Critical Care Course for Clinicians-Why, What, and How?
}

\author{
An Editorial for the Indian Journal of Surgery
}

\author{
Akshay Kumar $^{1} \cdot$ Richa Aggarwal $^{2} \cdot$ Ajay Kumar Sharma $^{3}$ \\ Received: 26 February 2021 / Accepted: 26 February 2021/Published online: 4 March 2021 \\ (C) Association of Surgeons of India 2021
}

Surgical residents in India are not formally trained in applying simple principles of applied physiology in managing deteriorating patients. The resuscitation skill development at the undergraduate level is highly variable, and critical care is mostly inaccessible to most patients who have to self-pay [1]. Naeem $\mathrm{N}$ and Montenegro $\mathrm{H}$ suggested that a prompt and wellrehearsed scientific approach would save unstable surgical patients from deterioration, in contrast to ineffective and costly "last-minute heroics" interventions in intensive therapy care units (ICTU) [2]. Prayag S [1] and Misra MC [3] highlighted that critical care training did not exist in India at either the undergraduate level or postgraduate level. If surgical trainees can be trained in skills based on applied physiology, they can identify and manage unwell patients in a timely fashion, as emphasized by White RJ and Garrioch MA [4],Goldacre MJ et al. [5],Smith GB and Poplett [6, 7]. Jones D et al. reported that the introduction of medical emergency teams (MET) who are skilled in resuscitation reduced intensive care unit admissions secondary to cardiac arrest in the wards [8].

Improved outcomes have also been noted with the establishment of HDUs acrosstertiary care institutions in both the public and private sectors, similar to that reported by Peter JV et al. [9] and Divatia JV et al [10]. Tissingh E et al. emphasized that courses like advanced trauma life support (ATLS) and care of critically ill surgical patient (CCrISP) are compulsory for UK trainees [11], however such courses are not

Richa Aggarwal

pathakricha@yahoo.co.in

1 Department of Emergency Medicine, All India Institute of Medical Sciences, New Delhi, India

2 Critical and Intensive Care, JPN Apex Trauma Centre, All India Institute of Medical Sciences, New Delhi, India

3 Royal Liverpool University Hospital, Core Surgical Training Merseyside, North West of England Deanery 2014-9, University of Liverpool, Liverpool, England deemed necessary in India. Though Basic Life Support (BLS) teaching, by lecture and by demonstration, is a component of the undergraduate curriculum in India, the competence in providing BLS is not tested before starting responsibilities for patient care. Currently, the exit examination of surgical trainees in any subspecialty in India is limited to testing their knowledge rather than assessing their competence. Simulation-based courses such as acute critical care course (ACCC), indigenously developed in India, are aimed to address these deficiencies in training and assessment. ACCC was introduced for providing training to surgery residents (medical and surgical trainees) and interns in India in 2014. Since then, 26 courses have been organized in 14 medical colleges training 607 interns and residents.

To provide optimal and seamless care, the surgeons ought to be equipped with the techniques of managing a critically ill patient in critical care. ACCC is a significant step towards bridging the gap that has resulted from undergraduate and postgraduate education, focused on imparting knowledge rather than developing practical skills (technical and nontechnical) in providing safe critical care. Deteriorating patients can be identified well in time if the residents are endowed with certified competence in applying simple principles of applied physiology.

It is worth highlighting a few critical clinical situations that surgical trainees are expected to manage but is not formally trained in doing so: it is a common practice to commence vasoactive drugs (such as dopamine or noradrenaline drip) without optimizing pre-load as a knee-jerk reflex for the management of hypotension in a surgical ward. That step is unnecessary and potentially hazardous in a ward setting. If a patient needs an ionotropic infusion, it requires ICTU monitoring. Several surgical/trauma patients need respiratory support or dialysis for kidney injury and require intensive monitoring. The surgical trainees are not comfortable in assessing respiratory support requirements, central nervous system involvement and metabolic derangements. S. Prayag reported that there had been a persistent gap between demand and 
supply of critical care facilities in India [1]. The surgeons need to appreciate the need to prevent the domino effect of singleorgan failure resulting in multi-organ failure. These validated and certified skills should be integral to the early stage of surgical training in India, the way it is the norm in the UK (www.jcst.org, www.gmc-uk.org, and www.rcseng.ac.uk/ education). Surgical critical care is an inseparable part of surgical training defined by the American Board of Surgery (www.absurgery.org/default.jsp?examoffered_scc). In 2012, a 1-day skill development course (a prototype of ACCC) was introduced for updating the nurses, paramedics, and junior doctors in a tribal area in central India in Jan Swasthya Sahyog (JSS) in District Bilaspur (state of Chattisgarh, India) (https://www.theguardian.com/global-development/video/ 2013/jan/07/india-healthcare-video?CMP=share_btn_link). That prototype of ACCC was based on interactive lecture delivered in Hindi to ensure that the lack of confidence in using English does not become a linguistic barrier.

J Ali et al. demonstrated how ATLS course was established in an Indian rural setting [12]. Theteam at AIIMS formulated a ACCC consensus committee consisting of 8 members to develop ACCC course material over 10 months in 2014 by using that infrastructure and expertise.

Many surgery teachers and critical care consultants from UK, India, and Australia joined hands to develop and refine ACCC. The whole process of taking ACCC to other medical schools included the following crucial steps: identifying, inspiring, training, and developing the faculty members who can deliver this proposed change at the local, regional, and national levels. The technical and non-technical (human factors) skills are crucial for providing effective care of sick surgical patients. A reliable and validated system of obligatory monitoring of competence of medics and nurses is non-existent in India. Moreover, there is a huge variation in quality of training at undergraduate and postgraduate levels in India. Simulation, except for a few teaching hospitals, is not used in medical and surgical training in India. Moreover, the violence against health care professionals is at unprecedented levels in India. Skill development in communication would address this unenviable situation. Teaching methodology of ACCC is dependent on high emphasis on interaction during lectures, utilizing Pendleton technique for feedback to students, using Peyton's method for skill development at small group stations, and testing candidates using moulages through "role play." [13, 14] ACCC also led to an innovative model of communication in the emergency care setting which was evolved by authors and published [15].

Competency development by skill-based learning is the need of the hour. ACCC has been conceptualized, developed, implemented, and fine-tuned to achieve these objectives.
Surgical residents and interns should be able to apply the principles of physiology in providing effective critical care. ACCC training would help surgical residents in systematically managing their deteriorating patients. Sharing "the vision document of ACCC" with senior management of teaching hospitals and with the deans of medical schools is the first crucial step.

\section{References}

1. Prayag S (2002) ICUs worldwide: critical care in India. Crit Care 6(6):479-480

2. Naeem N, Montenegro H (2005) Beyond the intensive care unit: a review of interventions aimed at anticipating and preventing inhospital cardiopulmonary arrest. Resuscitation 67(1):13-23

3. Mishra MC (2013) ATLS Subcommittee; International ATLS working group. Advanced trauma life support (ATLS®): the ninth edition. J Trauma Acute Care Surg 74(5):1363-1366

4. White RJ, Garrioch MA (2002) Time to train all doctors to look after seriously ill patients - CCrISP and IMPACT. Scott Med J 47: 127

5. Goldacre MJ, Lambert T, Evans J, Turner G (2003) Preregistration house officers' views on whether their experience at medical school prepared them well for their jobs: national questionnaire survey. BMJ. 326:1011-1012

6. Smith GB, Poplett N (2002) Knowledge of aspects of acute care in trainee doctors. Postgrad Med J 78:335-338

7. Smith GB, Poplett N (2004) Impact of attending a 1-day multiprofessional course (ALERTTM) on the knowledge of acute care in trainee doctors. Resuscitation 61:117-122

8. Jones D, George C, Hart GK, Bellomo R, Martin J (2008) Introduction of Medical Emergency Teams in Australia and New Zealand: a multi-centre study. Crit Care 12:R46

9. Peter JV, Thomas K, Jeyaseelan L, Yadav B (2016) Cost of intensive care in India. Int J Technol Assess Health Care 32(4):241-245

10. Divatia JV, Amin PR, Ramakrishnan N (2016) Intensive care in India: The Indian Intensive Care Case Mix and Practice Patterns Study. Indian J Crit Care Med 20(4):216-225

11. Tissingh E, Hayley Allan H, Vig S (2014) Courses for surgical trainees. BMJ 348:g3323

12. Ali J, Kumar S, Gautam S, Sorvari A, Misra MC (2015) Improving trauma care in India: the potential role of the Rural Trauma Team Development Course (RTTDC). Indian J Surg 77(Suppl 2):227231

13. Sokhal N, Kumar A, Aggarwal R, Sharma AK et al. (In press) Introducing acute critical care course for interns to develop competence, not just knowledge transfer. Accepted in NMJI

14. Kumar A, Sokhal N, Goyal K et al. (In press) Communication skills training through role play in the acute critical care course. Accepted in NMJI

15. Kumar A, Aggarwal R, Bhoi S, Sharma AK (Dec 2019) Small bursts of frequent communications- an effective communication method in a busy emergency department. Indian J Surg 81(6): 513-515

Publisher's Note Springer Nature remains neutral with regard to jurisdictional claims in published maps and institutional affiliations. 